\title{
A greater number of dissected lymph nodes is associated with more favorable outcomes in bladder cancer treated by radical cystectomy: a meta-analysis
}

\author{
Fei $\mathrm{Li}^{1,}{ }^{*}$, Xuwei Hong ${ }^{1, *}$, Lina Hou ${ }^{2, *}$, Fengsheng Lin ${ }^{1}$, Pengliang Chen ${ }^{1}$, Shiyu Pang ${ }^{1}$, \\ Yuejun Du ${ }^{1, *}$, He Huang ${ }^{3, *}$, Wanlong Tan ${ }^{1, *}$ \\ ${ }^{1}$ Department of Urology, Nanfang Hospital, Southern Medical University, Guangzhou, Guangdong 510515, P.R.China \\ ${ }^{2}$ Department of Healthy Management, Nanfang Hospital, Southern Medical University, Guangzhou, Guangdong 510515, P. R. \\ China \\ ${ }^{3}$ Department of Urology, The Third People's Hospital of Hubei Province, Wuhan, Hubei 430415, P. R. China \\ "These authors contributed equally to this work
}

Correspondence to: Wanlong Tan, email: twl@smu.edu.cn

He Huang, email: water201405@163.com

Yuejun Du, email: yunjun du1975@163.com

Keywords: bladder cancer, lymph node dissection, radical cystectomy, outcome, meta-analysis

Received: April 17, $2016 \quad$ Accepted: August 10, $2016 \quad$ Published: August 17, 2016

\section{ABSTRACT}

The optimal extent of lymph node dissection (LND) is currently not established, and the debate regarding the association between the number of dissected nodes and the outcomes of bladder cancer treated by radical cystectomy (RC) is still ongoing. Therefore, the present meta-analysis was performed to clarify this potential relationship. Eligible studies were retrieved via an electronic search for studies published up to April 2016, and by manual review of the references. A total of 25 cohort studies involving $\mathbf{4 1 , 4 0 0}$ bladder cancer patients who underwent RC were included. The summary relative risk estimates (SRRE) based on the highest compared with the lowest categories of LND were estimated by variance-based meta-analysis. Heterogeneity among the study results was explored through stratified analyses. Overall, bladder cancer patients with the highest category of LND had $28 \%, 34 \%$ and $36 \%$ reduced risks, corresponding to overall survival (SRRE $=0.72 ; 95 \% \mathrm{CI}, 0.64-0.80$ ), cancerspecific survival (SRRE $=0.66 ; 95 \% \mathrm{CI}, 0.54-0.80$ ) and recurrence-free survival (SRRE $=0.64 ; 95 \%$ CI, 0.50-0.82), respectively, compared with patients with the lowest category of LND. In summary, the patients with a greater number of dissected lymph nodes had statistically significant survival advantages in terms of the outcomes of bladder cancer following RC. The number of dissected lymph nodes could be an independent prognostic factor for bladder cancer. These findings need to be validated in prospective and larger epidemiological studies with a longer follow-up period.

\section{INTRODUCTION}

Worldwide, bladder cancer is among the most common malignancies of the genitourinary tract, particularly for men, in whom the incidence of this disease is three- to five-times greater than in women [1]. Approximately $70-80 \%$ of new cases are diagnosed as non-muscle-invasive or superficial bladder cancer. Furthermore, $>50 \%$ of these cancers will recur, despite treatment by transurethral resection combined with intravesical chemotherapy, and 10-20\% of recurrent tumors eventually progress to muscle invasive tumors [2]. At present, radical cystectomy (RC) with pelvic lymph node dissection (LND) is the gold standard for high-risk non-muscle-invasive and muscle-invasive bladder cancer. However, advances in this therapeutic strategy are still associated with unfavorable clinical outcomes and have a limited effect on increasing survival rate [3]. Currently, the stage and grade of tumors are used as the major prognostic factors for these patients, but there is growing interest in identifying additional prognostic indicators to aid medical professionals in improving prognostic evaluations [4]. 
$\mathrm{RC}$ and pelvic LND are important approaches used in the management of muscle-invasive bladder cancer, and LND is considered to be one of the most important steps of the surgery [5]. The number of dissected nodes is an important factor in determining an accurate nodal status; however, there is still an ongoing debate regarding the optimal number of nodes that should be dissected during RC [4]. The potential correlation between the number of dissected nodes and the outcomes of bladder cancer treated with $\mathrm{RC}$ has received much attention since 2000 [6-10]; however, a consensus has still not been reached, and a comprehensive assessment concerning the association has not been conducted.

In response, the current study presents the first metaanalysis performed to clarify the potential association between the number of dissected nodes and the outcomes of bladder cancer treated with RC, on the basis of findings from all published epidemiological studies.

\section{RESULTS}

\section{Literature search results}

Figure 1 shows a flow chart of the selection process used in the present study. A total of 2,757 articles were identified via our search strategy. Of the identified articles, 201 were selected for further review following exclusion of duplicate articles and an initial screening of the titles and abstracts. Furthermore, 86 articles were excluded because they did not evaluate the number of dissected lymph nodes, were not prognostic analyses, or were only published as meeting abstracts. After assessing the remaining 115 articles by full-text review, 90 articles were excluded: 45 articles were excluded as they did not investigate the association between the number of dissected nodes and the survival outcomes of bladder cancer after RC; 23 articles were excluded because they did not describe survival outcomes as overall survival (OS), cancer-specific survival (CSS), or recurrence-free survival (RFS); 19 articles were excluded as the number of nodes excised at LND was expressed as a continuous variable; and the other 3 articles were excluded as its participants overlapped with another study [11-13]. Finally, a total of 25 articles were included in the present meta-analysis (Figure 1).

\section{Characteristics of the studies}

The characteristics of the included studies are presented in Table 1. All the included studies were published between 2003 and 2015. The mean period of follow-up ranged from 6-120 months. Of these 25 studies, 10 were conduced in the United States of America [8, 14-22], 4 in Japan [10, 23-25], 2 in Canada [6, 26], 2 in German y [7, 27], 2 in Turkey [9, 28], 2 in international centers [29, 30], and one each in Italy [31], Denmark [32] and Korea [33]. The majority of the included studies used a retrospective design. The meta-analysis comprised a total sample size of 41,400 bladder cancer patients who underwent $\mathrm{RC}$, of which 6,044 patients were reported to have lymph node metastasis.

\section{Number of dissected nodes and OS of bladder cancer patients}

Figure 2 shows the pooled results for the OS of bladder cancer patients using a random-effects model based on 13 studies, with a sample size of 34,128 individuals. An inverse association was identified between the highest vs. the lowest category of LND and the OS rates of bladder cancer patients treated with RC [summary relative risk estimate $(\mathrm{SRRE})=0.72 ; 95 \% \mathrm{CI}, 0.64-0.80$ ) . Substantial heterogeneity was observed across studies ( $p$-value for heterogeneity $<0.001 ; \mathrm{I}^{2}=67.2 \%$; Figure 2 ). No statistical evidence of publication bias was indicated by the Begg's test ( $p=0.161)$, but the Egger's test indicated the possible presence of publication bias $(p=0.003)$. Among the subgroup analyses, the majority of results were found to be consistent with the primary findings. However, no significant associations were identified in the models of OS stratified by mean age $<65$ years $(\mathrm{SRRE}=0.76 ; 95 \%$ CI, 0.53-1.11) or by studies conducted in Asia (SRRE = 0.68 ; 95\% CI, 0.40-1.16) Table 2.

\section{Number of dissected nodes and CSS of bladder cancer patients}

The outcomes of bladder cancer were presented as CSS in 14 studies with a total of 12,518 bladder cancer patients. A decreased risk, corresponding to a higher CSS rate of bladder cancer patients was found in the patients in whom a greater number of nodes were removed during $\mathrm{RC}$ (SRRE $=0.66$; 95\% CI, 0.54-0.80; Figure 3), with evidence of heterogeneity observed ( $p$-value for heterogeneity $\left.<0.001 ; \mathrm{I}^{2}=73.3 \%\right)$. There was no statistical evidence of publication bias among the studies indicated by the Begg's or Egger's tests (Begg, $p=$ 0.189; Egger, $p=0.072$ ). Furthermore, inconsistent pooled results were found in the meta-analysis of CSS stratified by studies conducted in Europe (SRRE $=0.91 ; 95 \%$ CI, $0.62-1.34$ ) Table 2.

\section{Number of dissected nodes and RFS of bladder cancer patients}

The association between the number of dissected nodes and the RFS of bladder cancer patients following RC was reported in 9 studies, including 4,387 bladder cancer patients. The summarized result of these studies indicated that a significant inverse association was observed 
between the highest vs. the lowest category of LND and the RFS of bladder cancer following RC, with an SRRE of 0.64 (95\% CI, 0.50-0.82; Figure 4), and evidence of heterogeneity being found among the studies ( $p$-value for heterogeneity $\left.<0.001 ; \mathrm{I}^{2}=72.5 \%\right)$. The Begg's $(p=0.175)$ and Egger's tests $(p=0.224)$ provided no evidence of a significant publication bias among the studies on RFS. In addition, no significant association was also observed among studies of RFS when restricted to studies with a sample size of $<500$ patients $(\mathrm{SRRE}=0.59 ; 95 \%$ CI, 0.34-1.03), a mean age of $<65$ years $(\mathrm{SRRE}=0.74$;
95\% CI, 0.21-2.55), or studies conducted in Asia (SRRE = 0.59; 95\% CI, 0.09-4.06) Table 2.

\section{Sensitivity analyses}

Sensitivity analyses were performed by sequentially excluding each study in turn to examine the influence of individual studies on the overall or stratified estimates. None of the studies considerably affected the pooled effects observed in the meta-analysis (data not shown).

2757 articles identified through literature search

Pubmed:1229; Embase:1528; Cochrance: 40

873 duplicate articles

1884 articles after duplicates removed reviewed

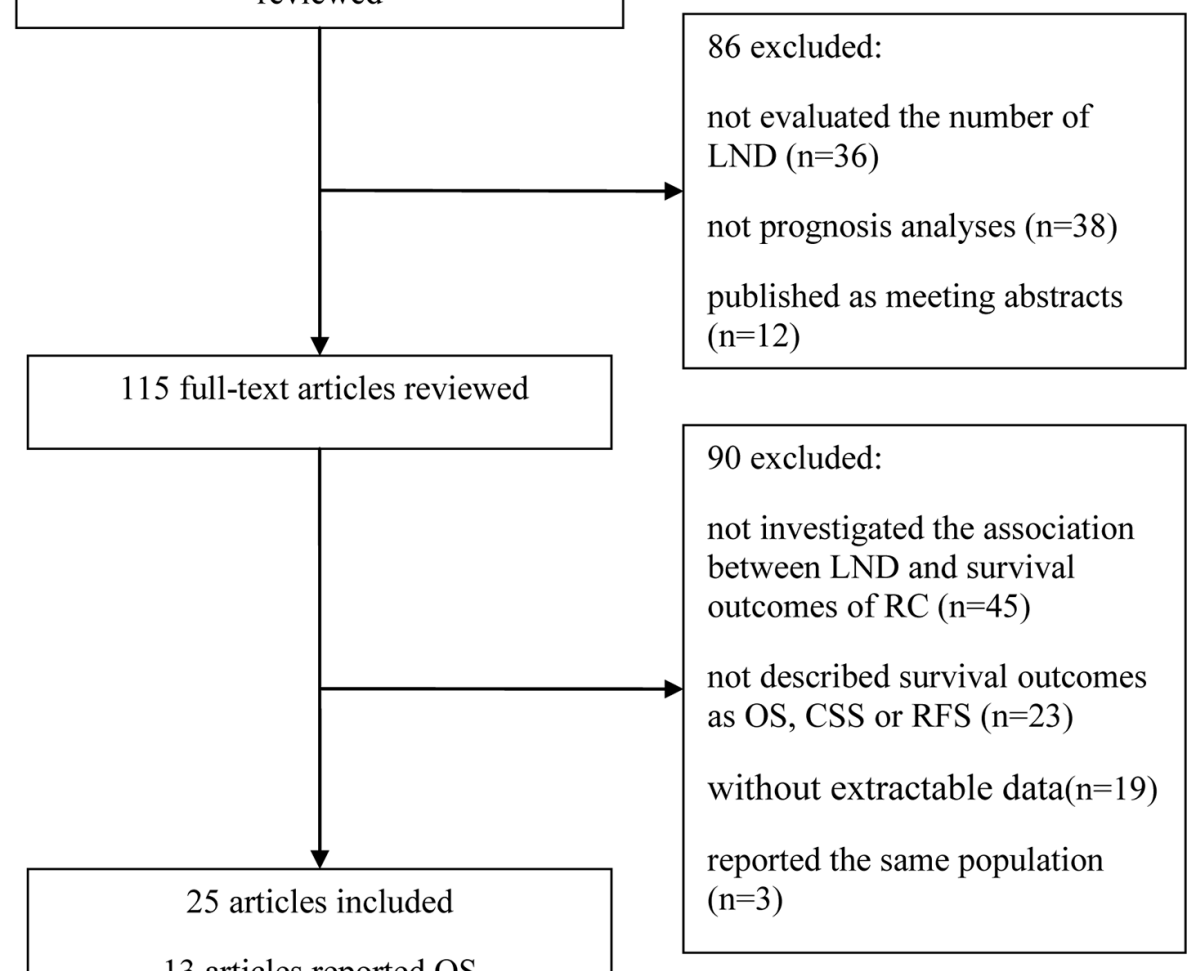

13 articles reported OS

14 articles reported CSS

9 articles reported RFS

Figure 1: Flow chart for the selection of studies.

1683 excluded: not relevant studies, mechanism studies, case reports, reviews, meta-analyses, comments, etc

not evaluated the number of

published as meeting abstracts $(n=12)$

90 excluded

not investigated the association between LND and surviva not described survival outcomes as OS, CSS or RFS $(n=23)$

without extractable data(n=19) same population $(n=3)$ 
Table 1: Characteristics of studies included in the meta-analysis of the number of dissected lymph nodes and outcomes of bladder cancer following radical cystectomy

\begin{tabular}{|c|c|c|c|c|c|c|c|c|c|c|}
\hline \multirow{2}{*}{ Author } & \multirow{2}{*}{ Country } & \multirow{2}{*}{ Period } & \multirow{2}{*}{$\begin{array}{c}\text { Follow-up } \\
\text { (months) }\end{array}$} & \multirow{2}{*}{$\begin{array}{l}\text { Sample } \\
\text { size }\end{array}$} & \multirow{2}{*}{$\begin{array}{c}\text { Mean age } \\
\text { (years) }\end{array}$} & \multirow{2}{*}{$\begin{array}{c}\text { T stage (number of } \\
\text { cases) }\end{array}$} & \multirow{2}{*}{$\begin{array}{l}\text { Extent of LND } \\
\text { (high vs. low) }\end{array}$} & \multicolumn{3}{|c|}{ Outcomes of bladder cancer } \\
\hline & & & & & & & & OS & CSS & RFS \\
\hline Ugurlu $2015^{[31]}$ & Turkey & $2005 \sim 2009$ & 44.9 & 85 & 61.0 & $\leq \mathrm{T} 2: 42 \geq \mathrm{T} 3: 43$ & $\geq 20$ vs. $<20$ & $1.17(0.76-1.81)$ & & $1.38(0.91-2.10)$ \\
\hline Siemens $2015^{[6]}$ & Canada & $1994 \sim 2008$ & NR & 1443 & 69.1 & $\begin{array}{c}\leq \mathrm{T} 2: 382 \geq \mathrm{T} 3: \\
1061\end{array}$ & $>13$ vs. $<5$ & $0.75(0.64-0.89)$ & $0.74(0.61-0.89)$ & \\
\hline Kang $2015^{[36]}$ & Korea & 1999 2012 & 38.0 & 385 & 66.0 & $\leq \mathrm{T} 2: 246 \geq \mathrm{T} 3: 139$ & $\geq 20$ vs. $<20$ & $0.41(0.23-0.71)$ & $0.47(0.25-0.85)$ & \\
\hline Zehnder $2014^{[32]}$ & International centers & NR & 110.4 & 521 & 66.9 & $\leq \mathrm{T} 2: 134 \geq \mathrm{T} 3: 387$ & $\geq 20$ vs. $<20$ & $0.66(0.52-0.84)$ & & $0.71(0.59-0.92)$ \\
\hline Ploussard $2014^{[33]}$ & International centers & 1979 2012 & 32.0 & 8141 & 68.0 & $\begin{array}{l}\leq \mathrm{T} 2: 4624 \\
\geq \mathrm{T} 3: 3517\end{array}$ & $\geq 20$ vs. $<20$ & $0.90(0.84-0.96)$ & & \\
\hline Lin $2014{ }^{[17]}$ & USA & $1990 \sim 2010$ & 65.9 & 196 & 68.0 & NR & $\geq 20$ vs. $<20$ & & & $0.37(0.14-1.02)$ \\
\hline Gray $2014^{[18]}$ & USA & $1998 \sim 2009$ & 43.0 & 16,953 & 67.0 & $\begin{array}{c}\leq \mathrm{T} 2: 1525 \geq \mathrm{T} 3: \\
15314\end{array}$ & $\geq 10$ vs. 0 & $0.76(0.68-0.86)$ & & \\
\hline Froehner $2014^{[7]}$ & Germany & $1993 \sim 2010$ & 93.6 & 735 & 67.0 & NR & $>20$ vs. $<10$ & $0.63(0.46-0.87)$ & & \\
\hline Simone $2013^{[34]}$ & Italy & $2002 \sim 2010$ & NR & 933 & 66.3 & $\leq \mathrm{T} 2: 463 \geq \mathrm{T} 3: 470$ & $\geq 27$ vs. $<27$ & & $0.73(0.56-0.95)$ & $0.70(0.56-0.88)$ \\
\hline Baumann $2013^{[19]}$ & USA & $1990 \sim 2008$ & 44.1 & 442 & 65.8 & $\leq \mathrm{T} 2: 232 \geq \mathrm{T} 3: 210$ & $\geq 10$ vs. $<10$ & & & $0.37(0.24-0.57)$ \\
\hline Otto $2012^{[30]}$ & Germany & $1989 \sim 2008$ & 42.0 & 2483 & 66.4 & $\begin{array}{l}\leq \mathrm{T} 2: 1377 \\
\geq \mathrm{T} 3: 1107\end{array}$ & $>14$ vs. $\leq 14$ & & $1.26(0.96-1.67)$ & \\
\hline Morgan $2012^{[8]}$ & USA & $1992 \sim 2006$ & NR & 3170 & 75.0 & $\begin{array}{c}\leq \mathrm{T} 2: 1158 \geq \mathrm{T} 3: \\
2003\end{array}$ & $\geq 14$ vs. $1-5$ & $0.77(0.66-0.90)$ & $0.78(0.65-0.93)$ & \\
\hline Karadeniz $2011^{[9]}$ & Turkey & $1996 \sim 2009$ & 20.0 & 74 & 61.7 & $\leq \mathrm{T} 2: 30 \geq \mathrm{T} 3: 44$ & $13-41$ vs. $1-12$ & $0.62(0.46-0.84)$ & $0.70(0.49-1.00)$ & \\
\hline Shirotake $2010^{[26]}$ & Japan & 1987 2008 & 64.0 & 169 & 68.0 & $\leq \mathrm{T} 2: 86 \geq \mathrm{T} 3: 83$ & $\geq 9$ vs. $<9$ & & $0.29(0.11-0.67)$ & \\
\hline Hugen $2010^{[20]}$ & USA & $1996 \sim 2008$ & NR & 260 & 66.9 & $\leq \mathrm{T} 2: 169 \geq \mathrm{T} 3: 91$ & $\geq 14$ vs. $<14$ & & & $0.78(0.62-0.97)$ \\
\hline Furukawa $2010^{[27]}$ & Japan & $1995 \sim 2003$ & NR & 82 & 70.3 & $\leq \mathrm{T} 2: 19 \geq \mathrm{T} 3: 63$ & $\geq 10$ vs. $<10$ & & $0.99(0.56-1.75)$ & \\
\hline Fang $2010^{[21]}$ & USA & $2000 \sim 2008$ & NR & 349 & 66.0 & $\leq \mathrm{T} 2: 191 \geq \mathrm{T} 3: 158$ & $\geq 16$ vs. $0-7$ & $0.51(0.30-0.85)$ & & \\
\hline Fairey $2009^{[29]}$ & Canada & 1994 2007 & 31.0 & 468 & 66.0 & $\leq \mathrm{T} 2: 230 \geq \mathrm{T} 3: 238$ & $\geq 11$ vs. 0 & $0.74(0.47-1.16)$ & $0.94(0.55-1.61)$ & \\
\hline Kassouf $2008^{[22]}$ & USA & $1993 \sim 2003$ & 24.0 & 248 & NA & $\leq \mathrm{T} 2: 57 \geq \mathrm{T} 3: 191$ & $>12$ vs. $\leq 12$ & & $0.41(0.29-0.58)$ & \\
\hline Ide $20088^{[28]}$ & Japan & $1987 \sim 2003$ & 42.0 & 146 & 67.0 & $\leq \mathrm{T} 2: 86 \geq \mathrm{T} 3: 60$ & $\geq 8$ vs. $<8$ & & & $0.19(0.04-0.91)$ \\
\hline Honma $2006^{[10]}$ & Japan & $1990 \sim 2002$ & 35.0 & 146 & 65.0 & $\leq \mathrm{T} 2: 90 \geq \mathrm{T} 3: 56$ & $\geq 13$ vs. $<13$ & & $0.11(0.03-0.40)$ & \\
\hline Lotan $2005^{[23]}$ & USA & $1984 \sim 2003$ & 46.8 & 750 & 64.8 & $\leq \mathrm{T} 2: 441 \geq \mathrm{T} 3: 309$ & $>25$ vs. $<13$ & $0.66(0.44-0.97)$ & $0.44(0.25-0.77)$ & $0.39(0.24-0.64)$ \\
\hline Stein $2003^{[24]}$ & USA & 1971 1997 & 120.0 & 1054 & 66.0 & NR & $>15$ vs. $\leq 15$ & $0.55(0.37-0.80)$ & & $0.73(0.45-1.19)$ \\
\hline Konety $2003^{[25]}$ & USA & $1988 \sim 1996$ & 63.5 & 1923 & 64.3 & $\leq \mathrm{T} 2: 399 \geq \mathrm{T} 3: 765$ & $\geq 20$ vs. 0 & & $0.48(0.30-0.76)$ & \\
\hline Knap $2003^{[35]}$ & Denmark & $1992 \sim 1998$ & 6.3 & 244 & 65.0 & $\leq \mathrm{T} 2: 205 \geq \mathrm{T} 3: 39$ & $\geq 12$ vs. $1-3$ & & $0.80(0.50-1.30)$ & \\
\hline
\end{tabular}

LND: Lymph node dissection; OS: Overall survival; CSS: Cancer-specific survival; RFS: Recurrence-free survival; NR: Not reported.

Study

ID

\begin{tabular}{|c|c|c|c|}
\hline Ugurlu 2015 & $\rightarrow$ & $1.17(0.76,1.81)$ & 4.57 \\
\hline Siemens 2015 & & $0.75(0.64,0.89)$ & 11.49 \\
\hline Kang 2015 & & $0.41(0.23,0.71)$ & 3.08 \\
\hline Zehnder 2014 & & $0.66(0.52,0.84)$ & 8.94 \\
\hline Ploussard 2014 & & $0.90(0.84,0.96)$ & 14.60 \\
\hline Gray 2014 & & $0.76(0.68,0.86)$ & 13.14 \\
\hline Froehner 2014 & & $0.63(0.46,0.87)$ & 6.77 \\
\hline Morgan 2012 & & $0.77(0.66,0.90)$ & 11.83 \\
\hline Karadeniz 2011 & & $0.62(0.46,0.84)$ & 7.20 \\
\hline Fang 2010 & & $0.51(0.30,0.85)$ & 3.49 \\
\hline Fairey 2009 & - & $0.74(0.47,1.16)$ & 4.32 \\
\hline Lotan 2005 & & $0.66(0.44,0.97)$ & 5.20 \\
\hline Stein 2003 & & $0.55(0.37,0.80)$ & 5.37 \\
\hline Overall (I-squared $=67.2 \%, \mathrm{p}=0.000)$ & & $0.72(0.64,0.80)$ & 100.00 \\
\hline NOTE: Weights are from random effects analysis & & & \\
\hline
\end{tabular}

Figure 2: Meta-analysis of studies that examined the association between the number of dissected nodes and overall survival (OS) following radical cystectomy. 


\section{DISCUSSION}

Approximately $35 \%$ of patients succumb to disease following $\mathrm{RC}$. The aim of $\mathrm{RC}$ is the complete eradication of local and regional disease, which is achieved by excision of the bladder, perivesical soft tissues, adjacent organs and regional lymph nodes [34]. Therefore, a number of different variables may affect survival outcomes following surgical intervention; these variables include lymph node status, surgical margin status, pathological stage and the number of lymph nodes dissected [35]. Although many studies have demonstrated that statistically significant survival advantages may be observed among groups of patients with a greater number of dissected nodes during $\mathrm{RC}[6,7,9,10]$, other studies have indicated that there is no significant association between the two [4, 14, 24]. Thus, reports in the literature regarding the correlation between the number of dissected nodes and the prognosis following $\mathrm{RC}$ are conflicting.

A substantial proportion of bladder cancer patients will have microscopic systemic spread at the time of surgery [35]. Of these patients, removing additional lymph nodes outside of the standard area will cure only a minority. Therefore, the therapeutic effects attained by extended LND are likely to be relatively small (if they exist), and studies with extremely large sample sizes are required to verify this. Certain biases (for instance, removing more lymph nodes in younger, healthier patients with early-stage disease) may result in great variability in outcome [10]. Remarkably, the survival outcomes reported in one study comparing extended with super-extended dissection were not better than in comparable series using standard dissection [36].

To the best of our knowledge, the present metaanalysis was the first to explore the potential relationship between the number of nodes removed at LND and the outcomes of bladder cancer patients treated with RC. We pooled 25 cohort studies, with a large sample size of $\sim 1,400$ bladder cancer patients who underwent $\mathrm{RC}$, in order to enhance the statistical power available to estimate the overall associations, and obtain a stable and credible result. Quantitative analysis of the published epidemiological studies indicated that the bladder cancer patients with a greater extent of LND during RC had statistically significant advantages in terms of OS, CSS and RFS, corresponding to reduced risks of $28 \%, 34 \%$ and $36 \%$, respectively, compared with patients with a lesser extent of LND.

A large degree of heterogeneity was observed across studies included in this analysis. However, an absence of

\begin{tabular}{|c|c|c|c|}
\hline Study & & & $\%$ \\
\hline ID & & $\operatorname{SRRE}(95 \% \mathrm{CI})$ & Weight \\
\hline Siemens 2015 & & $0.74(0.61,0.89)$ & 10.51 \\
\hline Kang 2015 & & $0.47(0.25,0.85)$ & 5.48 \\
\hline Simone 2013 & & $0.73(0.56,0.95)$ & 9.62 \\
\hline Otto 2012 & + & $1.26(0.96,1.67)$ & 9.46 \\
\hline Morgan 2012 & & $0.78(0.65,0.93)$ & 10.62 \\
\hline Karadeniz 2011 & & $0.70(0.49,1.00)$ & 8.42 \\
\hline Shirotake 2010 & & $0.29(0.11,0.67)$ & 3.37 \\
\hline Furukawa 2010 & & $0.99(0.56,1.75)$ & 5.89 \\
\hline Fairey 2009 & & $0.94(0.55,1.61)$ & 6.23 \\
\hline Kassouf 2008 & & $0.41(0.29,0.58)$ & 8.55 \\
\hline Honma 2006 & & $0.11(0.03,0.40)$ & 1.93 \\
\hline Lotan 2005 & & $0.44(0.25,0.77)$ & 5.97 \\
\hline Konety 2003 & & $0.48(0.30,0.76)$ & 7.06 \\
\hline Knap 2003 & - & $0.80(0.50,1.30)$ & 6.90 \\
\hline Overall (I-squared $=73.3 \%, p=0.000)$ & & $0.66(0.54,0.80)$ & 100.00 \\
\hline NOTE: Weights are from random effects analysis & & & \\
\hline
\end{tabular}

Figure 3: Meta-analysis of studies that examined the association between the number of dissected nodes and cancerspecific survival (CSS) following radical cystectomy. 
publication bias in these meta-analyses was shown using the Egger's and Begg's tests; one exception was the result of the Egger's test in the model of OS, which suggested possible publication bias. In addition, sensitivity analyses yielded similar and robust results, indicating that no study considerably affected the summary associations between the extent of LND and the outcomes of bladder cancer patients who underwent RC.

Heterogeneity is a significant concern in metaanalyses. Substantial heterogeneity was detected across the included studies, which may reflect differences in the study populations, analytical methodology and adjustment for confounding factors. Although subgroup analyses were performed to examine potential sources of heterogeneity, stratifying studies by mean age, sample size, study design, year of publication and geographical region, the possible source of heterogeneity was not identified. Differences in LND template, tissue submission technique, pathological evaluation and lymph node identification may lead to heterogeneity between the individual studies. The subgroup analyses based on the above four issues were not conducted due to limited data. In addition, we could not exclude the possibility of various other unknown factors contributing to the variability.

Concerning the significant inverse associations between the number of lymph nodes dissected and the outcomes of bladder cancer following $\mathrm{RC}$, one plausible explanation is that removal of more lymph nodes improves the thoroughness of the pathology evaluation, which may be beneficial in guiding more accurate disease staging and subsequent therapy [9, 15]. The findings underline the necessity for guidelines regarding surgical lymphadenectomy and the pathological assessment of lymph nodes in bladder cancer. Among the subgroup analyses, we identified inconsistent findings in certain subgroups, such as studies with a sample size of $<500$, studies reporting a mean age of $<65$ years, or those conducted in Asia or Europe. The reason for these inconsistent findings is uncertain. Possible explanations may be the limitations of the studies, different techniques used by surgeons or pathologists, different tumor stages, differences in subsequent therapies, adjusted factors, dietary factors, or other unmeasured or unknown factors [8, 37].

The present study has several important limitations that must be taken into account when considering its contribution to the field. First, and most significantly, are the limitations inherent to retrospective analyses, which accounted for the majority of included studies; studies with this design are susceptible to bias and may thus produce results that are difficult to interpret. Although there were some prospective cohort studies that met our inclusion criteria, they comprised a relatively small number of patients. Secondly, substantial heterogeneity was observed among the studies, although the possible sources of heterogeneity were not identified despite the conduction of several subgroup analyses. The pooled results in the

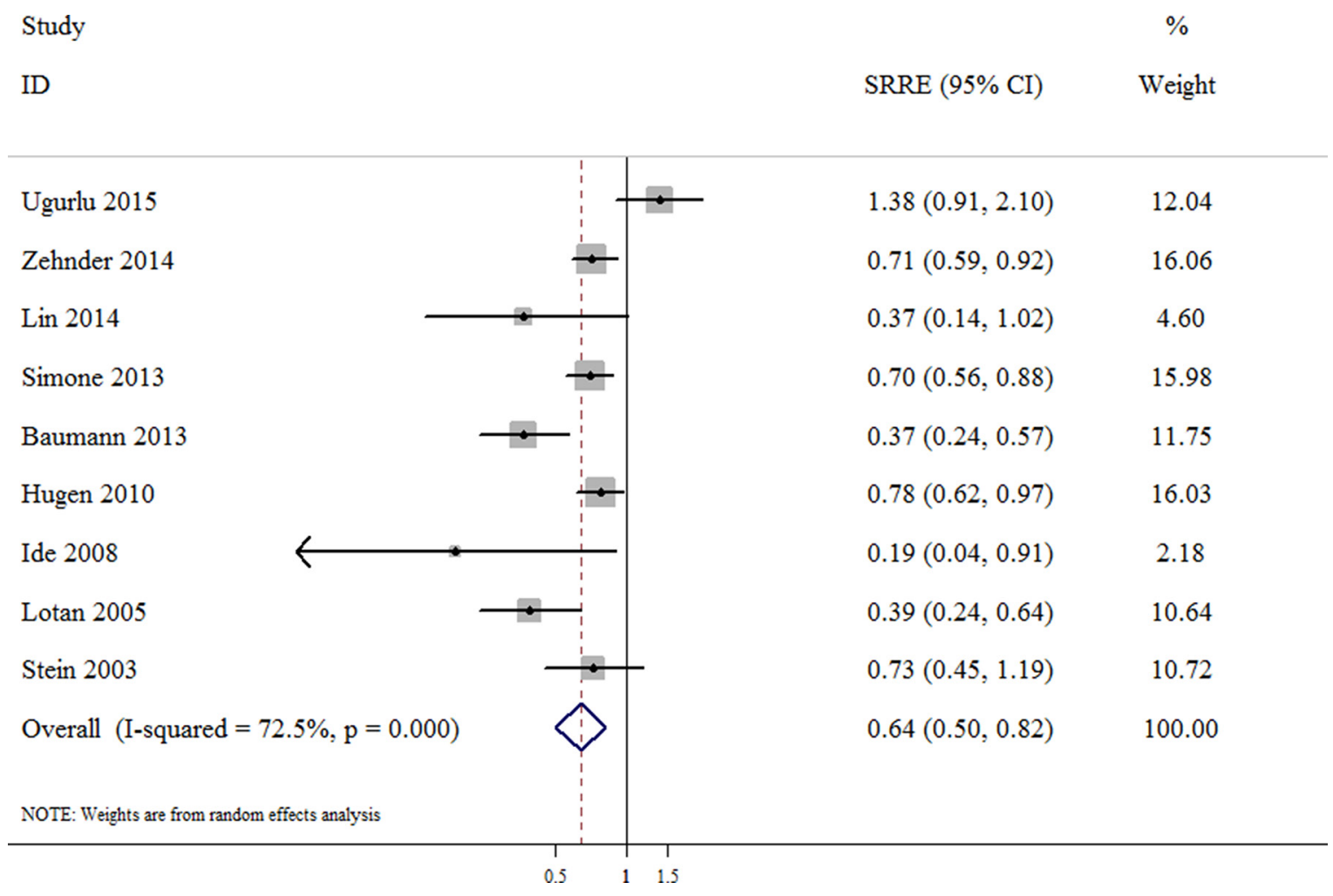

Figure 4: Meta-analysis of studies that examined the association between the number of dissected nodes and recurrencefree survival (RFS) following radical cystectomy. 
Table 2: Summary of meta-analysis results for the numbers of dissected lymph nodes and bladder cancer outcomes

\begin{tabular}{|c|c|c|c|c|}
\hline \multirow{2}{*}{ Analysis specification } & \multicolumn{4}{|c|}{ Highest category vs. lowest category } \\
\hline & Studies & SRRE $(95 \%$ CI $)$ & p-het & $I^{2}$ \\
\hline \multicolumn{5}{|l|}{ Overall survival } \\
\hline All & 13 & $0.72(0.64-0.80)$ & 0.000 & 67.2 \\
\hline \multicolumn{5}{|l|}{ Year of publication } \\
\hline$\geq 2011$ & 9 & $0.75(0.66-0.84)$ & 0.000 & 71.7 \\
\hline$<2011$ & 4 & $0.61(0.49-0.76)$ & 0.663 & 0.0 \\
\hline \multicolumn{5}{|l|}{ Sample size (cases) } \\
\hline$\geq 500$ & 8 & $0.74(0.67-0.83)$ & 0.003 & 68.0 \\
\hline$<500$ & 5 & $0.66(0.48-0.91)$ & 0.029 & 62.8 \\
\hline \multicolumn{5}{|l|}{ Mean age (years) } \\
\hline$\geq 65$ & 10 & $0.72(0.64-0.81)$ & 0.000 & 69.8 \\
\hline$<65$ & 3 & $0.76(0.53-1.11)$ & 0.052 & 66.2 \\
\hline \multicolumn{5}{|l|}{ Geographical region } \\
\hline America & 7 & $0.74(0.69-0.80)$ & 0.539 & 0.0 \\
\hline Europe & 1 & $0.63(0.46-0.87)$ & l & / \\
\hline Asia & 3 & $0.68(0.40-1.16)$ & 0.009 & 78.8 \\
\hline \multicolumn{5}{|l|}{ Cancer-specific survival } \\
\hline All & 14 & $0.66(0.54-0.80)$ & 0.000 & 73.3 \\
\hline \multicolumn{5}{|l|}{ Year of publication } \\
\hline$\geq 2011$ & 6 & $0.79(0.65-0.95)$ & 0.011 & 66.6 \\
\hline$<2011$ & 8 & $0.53(0.37-0.75)$ & 0.003 & 67.9 \\
\hline \multicolumn{5}{|l|}{ Sample size (cases) } \\
\hline$\geq 500$ & 6 & $0.74(0.59-0.93)$ & 0.001 & 75.3 \\
\hline$<500$ & 8 & $0.57(0.41-0.80)$ & 0.002 & 68.3 \\
\hline \multicolumn{5}{|l|}{ Mean age (years) } \\
\hline$\geq 65$ & 10 & $0.75(0.61-0.93)$ & 0.001 & 69.1 \\
\hline$<65$ & 3 & $0.56(0.42-0.75)$ & 0.271 & 23.5 \\
\hline \multicolumn{5}{|l|}{ Geographical region } \\
\hline America & 6 & $0.62(0.49-0.79)$ & 0.004 & 70.7 \\
\hline Europe & 3 & $0.91(0.62-1.34)$ & 0.016 & 75.7 \\
\hline Asia & 6 & $0.49(0.29-0.84)$ & 0.010 & 70.1 \\
\hline \multicolumn{5}{|l|}{ Recurrence-free survival } \\
\hline All & 9 & $0.64(0.50-0.82)$ & 0.000 & 72.5 \\
\hline \multicolumn{5}{|l|}{ Year of publication } \\
\hline$\geq 2011$ & 5 & $0.67(0.47-0.96)$ & 0.000 & 80.1 \\
\hline$<2011$ & 4 & $0.58(0.37-0.89)$ & 0.029 & 66.7 \\
\hline \multicolumn{5}{|l|}{ Sample size (cases) } \\
\hline$\geq 500$ & 4 & $0.65(0.53-0.80)$ & 0.158 & 42.3 \\
\hline$<500$ & 5 & $0.59(0.34-1.03)$ & 0.000 & 82.9 \\
\hline \multicolumn{5}{|l|}{ Mean age (years) } \\
\hline$\geq 65$ & 7 & $0.63(0.51-0.78)$ & 0.038 & 55.0 \\
\hline$<65$ & 2 & $0.74(0.21-2.55)$ & 0.000 & 93.2 \\
\hline \multicolumn{5}{|l|}{ Geographical region } \\
\hline America & 5 & $0.53(0.36-0.77)$ & 0.006 & 72.3 \\
\hline Europe & 1 & $0.70(0.56-0.88)$ & l & / \\
\hline Asia & 2 & $0.59(0.09-4.06)$ & 0.016 & 82.7 \\
\hline
\end{tabular}

SRRE: summary relative risk estimate.

majority of subgroup analyses were consistent the overall findings. Furthermore, our sensitivity analyses indicated the robustness of the current findings. Thirdly, the bladder cancer patients in the included studies underwent $\mathrm{RC}$ by multiple different surgeons, and their specimens were evaluated by different pathologists; variation in such practices could affect accurate clinical staging. Stage discrepancy remains a significant problem across all analyzed treatment facilities and affects the summary associations [38]. Furthermore, this variability may have contributed to the observed heterogeneity in this metaanalysis. However, this may also be regarded as a strength as it represents real-world practice.

In summary, the present analysis summarizes 
the available evidence that statistically significant advantages in the OS, CSS and RFS of bladder cancer may be achieved by the dissection of a greater number of lymph nodes during RC. The extent of LND may be an independent prognostic factor for bladder cancer. These findings must be validated in prospective and larger epidemiological studies with longer follow-up periods.

\section{MATERIALS AND METHODS}

\section{Search strategy}

The present meta-analysis was performed in accordance with the Preferred Reporting Items for Systematic Reviews and Meta-analyses (PRISMA) guidelines [39]. A systematic literature search was performed in PubMed, Embase and the Cochrane Library to identify the eligible studies published from the inception of the databases to April 2016. The primary search string included the following items: 'radical cystectomy', or 'bladder cancer', or 'transitional cell carcinoma', or 'urinary bladder neoplasms'; 'lymphadenectomy', or 'lymph node dissection', or 'lymph node excision', or 'lymph node removed'; 'outcome', or 'survival', or 'mortality', or 'recurrence'. Our search focused on human studies, without a restriction on language. In addition, the reference lists of all included articles we reviewed to identify additional available studies.

\section{Inclusion and excluded criteria}

The eligibility of each study was assessed by the population, intervention, comparator, outcome and study design (PICOS) approach [39]. Studies were included in the meta-analysis if they met the following criteria: the bladder cancer patient was treated with RC (P); the LND was performed during RC (I); the numbers of lymph nodes removed were evaluated $(\mathrm{C})$; risk estimates [hazard ratios, risk ratios, odd ratios] with corresponding 95\% CIs were reported, or sufficient data were provided to estimate these (O); the study design was a prospective or retrospective cohort study $(\mathrm{S})$.

In addition to these criteria, the survival outcomes of bladder cancer were defined as 'overall survival (OS)', 'cancer-specific survival (CSS)', and 'recurrence-free survival (RFS)', and these were synthesized respectively in the meta-analysis. The exclusion criteria were as follows: i) duplicates; ii) no usable data reported; iii) case-reports, reviews, expert opinions or meeting abstracts, cross-sectional, case-control and ecological analyses. In cases of more than one publication using the same or an overlapping cohort, only the most recent and informative one was included.

\section{Data extraction}

Two of the authors independently extracted the information from the selected studies using a standardized data collection form. Discrepancies that arose were resolved by repeating the review of the studies and the discussion. The following information was extracted: first author, year of publication, study design, study location, study period, duration of follow-up, sample size, mean age, gender, pathological stages, positive lymph node rate, the number of dissected nodes, and risk estimates of OS, CSS or RFS based on the highest vs. the lowest categories of the extent of LND. If a study reported multiple data sets, the results from the main multivariable model that included the most adjusted confounders were used.

\section{Statistical analysis}

The SRRE for the highest vs. the lowest category of LND was used. Most of the included studies used Cox proportional hazard ratio models to analyze the number of dissected nodes with regard to the survival outcomes of bladder cancer. From these studies, we used the reported hazard ratios and $95 \% \mathrm{CIs}$, or the reciprocally converted values for calculation. For studies that used the KaplanMeier method and log-rank test to estimate survival, the risk estimates and $95 \%$ CIs were calculated according to method described by Parmar et al. [40] and Altman et al. [41].

Fixed- and random-effects methods were both used in order to estimate the association between outcomes of bladder cancer treated with RC and the highest category of number of lymph nodes removed vs. the lowest category. Statistical heterogeneity among the studies was assessed using the Q statistic (with $P<0.10$ used as the threshold for significance). The $\mathrm{I}^{2}$ statistic was also calculated in order to quantitatively assess the inconsistency across studies, with values of 75,50 and $25 \%$ defined as representing high, medium and low degrees of heterogeneity, respectively. In addition, forest plots were constructed to evaluate the associations between the extent of LND and the various survival outcomes of bladder cancer treated with RC.

Subgroup analyses were performed to examine potential sources of heterogeneity according to the year of publication $(\geq 2011$ vs. $<2011)$, sample size $(\geq 500$ vs. $<500$ patients $)$, mean age $(\geq 65$ vs. $<65$ years $)$ and geographical region (America, Europe and Asia). Sensitivity analyses were also conducted to assess the robustness of the results, by repeating the meta-analysis after omitting one study at a time. Furthermore, Egger's test and Begg's method were applied to evaluate the possible bias, combined with a visual inspection of the funnel plot. All statistical analyses were conducted using STATA 12.0 (StataCorp LP, College Station, TX, USA). A two-tailed $P$ value of $<0.05$ was considered to indicate statistical significance, except where specifically noted.

\section{ACKNOWLEDGMENTS AND FUNDING}

This work was supported by Dean's Research Fund of Nanfang Hospital, the Southern Medical University (2013C022) (F.L.), the Natural Science Foundation of 
Guangdong Province of China [2014A030310424 (F.L.) and 2015A030313289 (W.L.T.)], Guangdong Provincial Science and Technology Projects (2013B022000067) (W.L.T.) and the National Natural Science Foundation of China (No. 81272844) (W.L.T.).

\section{CONFLICTS OF INTEREST}

We declare that we have no conflicts of interest.

\section{REFERENCES}

1. Li F, An S-1, Zhou Y, Liang Z-k, Jiao Z-j, Jing Y-m, Wan P, Shi $\mathrm{X}-\mathrm{j}$ and Tan W-1. Milk and dairy consumption and risk of bladder cancer: a meta-analysis. Urology. 2011; 78:1298-1305.

2. Li F, Zhou Y, Hu R-T, Hou L-N, Du Y-J, Zhang X-J, Olkkonen VM, Tan W-L. Egg consumption and risk of bladder cancer: a meta-analysis. Nutrition and cancer-an international journal. 2013; 65:538-546.

3. Karl A, Carroll PR, Gschwend JE, Knuchel R, Montorsi F, Stief CG, Studer UE. The impact of lymphadenectomy and lymph node metastasis on the outcomes of radical cystectomy for bladder cancer. European urology. 2009; 55:826-835.

4. Fransen van de Putte EE, Hermans TJN, Werkhoven EV, Mertens LS, Meijer RP, Bex A, Wassenaar AE, van der Poel HG, van Rhijn BWG, Horenblas S. Lymph node count at radical cystectomy does not influence long-term survival if surgeons adhere to a standardized template. Urologic Oncology: Seminars and Original Investigations. 2015.

5. Herr HW, Bochner BH, Dalbagni G, Donat SM, Reuter VE, Bajorin DF. Impact of the number of lymph nodes retrieved on outcome in patients with muscle invasive bladder cancer. The Journal of urology. 2002; 167:1295-1298.

6. Siemens DR, Mackillop WJ, Peng Y, Wei X, Berman D, Booth CM. Lymph node counts are valid indicators of the quality of surgical care in bladder cancer: A populationbased study. Urologic Oncology: Seminars and Original Investigations. 2015; 33:425.e415-425.e423.

7. Froehner M, Novotny V, Heberling U, Rutsch L, Litz RJ, Hübler M, Koch R, Baretton GB, Wirth MP. Relationship of the number of removed lymph nodes to bladder cancer and competing mortality after radical cystectomy. European urology. 2014; 66:987-990.

8. Morgan TM, Barocas DA, Penson DF, Chang SS, Ni S, Clark PE, Smith JA, Jr. and Cookson MS. Lymph node yield at radical cystectomy predicts mortality in nodenegative and not node-positive patients. Urology. 2012; 80:632-640.

9. Karadeniz T, Baran C, Topsakal M, Kavukcu E. Importance of the number of retreived lymph nodes during cystectomy. Urology journal. 2011; 8:197-202.
10. Honma I, Masumori N, Sato E, Maeda T, Hirobe M, Kitamura H, Takahashi A, Itoh N, Tamakawa M, Tsukamoto T. Removal of more lymph nodes may provide better outcome, as well as more accurate pathologic findings, in patients with bladder cancer-analysis of role of pelvic lymph node dissection. Urology. 2006; 68:543-548.

11. Tilki D, Shariat SF, Lotan Y, Rink M, Karakiewicz PI, Schoenberg MP, Lerner SP, Sonpavde G, Sagalowsky AI, Gupta A. Lymphovascular invasion is independently associated with bladder cancer recurrence and survival in patients with final stage T1 disease and negative lymph nodes after radical cystectomy. BJU international. 2013; 111:1215-1221.

12. Simone G, Papalia R, Ferriero M, Guaglianone S, Naselli A, Collura D, Introini C, Puppo P, Muto G, Gallucci M. Development and external validation of lymph node density cut-off points in prospective series of radical cystectomy and pelvic lymph node dissection. International journal of urology. 2012; 19:1068-1074.

13. Wright JL, Lin DW, Porter MP. The association between extent of lymphadenectomy and survival among patients with lymph node metastases undergoing radical cystectomy. Cancer. 2008; 112:2401-2408.

14. Lin J, Deibert CM, Holder D, Benson MC, McKiernan JM. The role of pelvic lymphadenectomy in non-muscle invasive bladder cancer. The Canadian journal of urology. 2014; 21:7108-7113.

15. Gray PJ, Lin CC, Jemal A, Shipley WU, Fedewa SA, Kibel AS, Rosenberg JE, Kamat AM, Virgo KS, Blute ML, Zietman AL, Efstathiou JA. Clinical-pathologic stage discrepancy in bladder cancer patients treated with radical cystectomy: results from the national cancer data base. International journal of radiation oncology, biology, physics. 2014; 88:1048-1056.

16. Baumann BC, Guzzo TJ, He J, Keefe SM, Tucker K, Bekelman JE, Hwang WT, Vaughn DJ, Malkowicz SB, Christodouleas JP. A novel risk stratification to predict local-regional failures in urothelial carcinoma of the bladder after radical cystectomy. International journal of radiation oncology, biology, physics. 2013; 85:81-88.

17. Hugen CM, Polcari AJ, Fitzgerald MP, Dauw C, Flanigan RC, Quek ML. Risk factors for recurrence following radical cystectomy for pathologic node negative bladder cancer. Journal of surgical oncology. 2010; 102:334-337.

18. Fang AC, Ahmad AE, Whitson JM, Ferrell LD, Carroll PR, Konety BR. Effect of a minimum lymph node policy in radical cystectomy and pelvic lymphadenectomy on lymph node yields, lymph node positivity rates, lymph node density, and survivorship in patients with bladder cancer. Cancer. 2010; 116:1901-1908.

19. Kassouf W, Agarwal PK, Herr HW, Munsell MF, Spiess PE, Brown GA, Pisters L, Grossman HB, Dinney CP, Kamat AM. Lymph node density is superior to TNM 
nodal status in predicting disease-specific survival after radical cystectomy for bladder cancer: analysis of pooled data from MDACC, MSKCC. Journal of clinical oncology. 2008; 26:121-126.

20. Lotan Y, Gupta A, Shariat SF, Palapattu GS, Vazina A, Karakiewicz PI, Bastian PJ, Rogers CG, Amiel G, Perotte P, Schoenberg MP, Lerner SP, Sagalowsky AI. Lymphovascular invasion is independently associated with overall survival, cause-specific survival, and local and distant recurrence in patients with negative lymph nodes at radical cystectomy. Journal of clinical oncology. 2005; 23:6533-6539.

21. Stein JP, Cai J, Groshen S, Skinner DG. Risk factors for patients with pelvic lymph node metastases following radical cystectomy with en bloc pelvic lymphadenectomy: concept of lymph node density. The Journal of urology. 2003; 170:35-41.

22. Konety BR, Joslyn SA, O’Donnell MA. Extent of pelvic lymphadenectomy and its impact on outcome in patients diagnosed with bladder cancer: analysis of data from the Surveillance, Epidemiology and End Results Program data base. The Journal of urology. 2003; 169:946-950.

23. Shirotake S, Kikuchi E, Matsumoto K, Yazawa S, Kosaka T, Miyajima A, Nakagawa K, Oya M. Role of pelvic lymph node dissection in lymph node-negative patients with invasive bladder cancer. Japanese journal of clinical oncology. 2010; 40:247-251.

24. Furukawa J, Miyake H, Terakawa T, Sakai I, Muramaki M, Takenaka A, Fujisawa M. Predictors of cancer-specific survival following radical cystectomy in patients with nodepositive bladder cancer. Current Urology. 2010; 4:188-192.

25. Ide H, Kikuchi E, Miyajima A, Nakagawa K, Ohigashi T, Nakashima J, Oya M. The predictors of local recurrence after radical cystectomy in patients with invasive bladder cancer. Japanese journal of clinical oncology. 2008; 38:360-364.

26. Fairey AS, Jacobsen NE, Chetner MP, Mador DR, Metcalfe JB, Moore RB, Rourke KF, Todd GT, Venner PM, Voaklander DC, Estey EP. Associations between comorbidity, and overall survival and bladder cancer specific survival after radical cystectomy: results from the Alberta Urology Institute Radical Cystectomy database. The Journal of urology. 2009; 182:85-92; discussion 93.

27. Otto W, May M, Fritsche HM, Dragun D, Aziz A, Gierth M, Trojan L, Herrmann E, Moritz R, Ellinger J, Tilki D, Buchner A, Hofner T, et al. Analysis of sex differences in cancer-specific survival and perioperative mortality following radical cystectomy: results of a large German multicenter study of nearly 2500 patients with urothelial carcinoma of the bladder. Gender medicine. 2012; 9:481-489.

28. Ugurlu O, Baltaci S, Aslan G, Can C, Cal C, Elhan A, Turkeri L, Mungan A. Does skip metastasis or other lymph node parameters have additional effects on survival of patients undergoing radical cystectomy for bladder cancer? Korean journal of urology. 2015; 56:357-364.
29. Zehnder P, Studer UE, Daneshmand S, Birkhauser FD, Skinner EC, Roth B, Miranda G, Burkhard FC, Cai J, Skinner DG, Thalmann GN, Gill IS. Outcomes of radical cystectomy with extended lymphadenectomy alone in patients with lymph node-positive bladder cancer who are unfit for or who decline adjuvant chemotherapy. BJU international. 2014; 113:554-560.

30. Ploussard G, Shariat SF, Dragomir A, Kluth LA, Xylinas E, Masson-Lecomte A, Rieken M, Rink M, Matsumoto K, Kikuchi E, Klatte T, Boorjian SA, Lotan Y, et al. Conditional survival after radical cystectomy for bladder cancer: evidence for a patient changing risk profile over time. European urology. 2014; 66:361-370.

31. Simone G, Papalia R, Ferriero M, Guaglianone S, Castelli E, Collura D, Muto G, Gallucci M. Stage-specific impact of extended versus standard pelvic lymph node dissection in radical cystectomy. International journal of urology. 2013; 20:390-397.

32. Knap MM, Lundbeck F, Overgaard J. The role of pelvic lymph node dissection as a predictive and prognostic factor in bladder cancer. European journal of cancer (Oxford, England : 1990). 2003; 39:604-613.

33. Kang M, Jeong CW, Kwak C, Kim HH, Ku JH. The Prognostic Significance of the Early Postoperative Neutrophil-to-Lymphocyte Ratio in Patients with Urothelial Carcinoma of the Bladder Undergoing Radical Cystectomy. Annals of surgical oncology. 2016; 23:335-342.

34. Stein JP, Lieskovsky G, Cote R, Groshen S, Feng AC, Boyd S, Skinner E, Bochner B, Thangathurai D, Mikhail M, Raghavan D, Skinner DG. Radical cystectomy in the treatment of invasive bladder cancer: long-term results in 1,054 patients. Journal of clinical oncology. 2001; 19:666-675.

35. Stenzl A, Cowan NC, De Santis M, Jakse G, Kuczyk MA, Merseburger AS, Ribal MJ, Sherif A, Witjes JA. The updated EAU guidelines on muscle-invasive and metastatic bladder cancer. European urology. 2009; 55:815-825.

36. Zehnder P, Studer UE, Skinner EC, Dorin RP, Cai J, Roth B, Miranda G, Birkhäuser F, Stein J, Burkhard FC, Daneshmand S, Thalmann GN, Gill IS, et al. Super extended versus extended pelvic lymph node dissection in patients undergoing radical cystectomy for bladder cancer: a comparative study. The journal of urology. 2011; 186:1261-1268.

37. Davies JD, Simons CM, Ruhotina N, Barocas DA, Clark PE, Morgan TM. Anatomic basis for lymph node counts as measure of lymph node dissection extent: a cadaveric study. Urology. 2013; 81:358-363.

38. Weight CJ, Garcia JA, Hansel DE, Fergany AF, Campbell SC, Gong MC, Jones JS, Klein EA, Dreicer R, Stephenson AJ. Lack of pathologic down-staging with neoadjuvant chemotherapy for muscle-invasive urothelial carcinoma of the bladder. Cancer. 2009; 115:792-799.

39. Liberati A, Altman DG, Tetzlaff J, Mulrow C, Gøtzsche PC, Ioannidis JP, Clarke M, Devereaux P, Kleijnen J, Moher D. 
The PRISMA statement for reporting systematic reviews and meta-analyses of studies that evaluate health care interventions: explanation and elaboration. Annals of internal medicine. 2009; 151:W-65-W-94.

40. Parmar MK, Torri V, Stewart L. Extracting summary statistics to perform meta-analyses of the published literature for survival endpoints. Statistics in medicine. 1998; 17:2815-2834.

41. Altman DG, Bland JM. How to obtain the confidence interval from a $P$ value. BMJ. 2011; 343:d2090. 